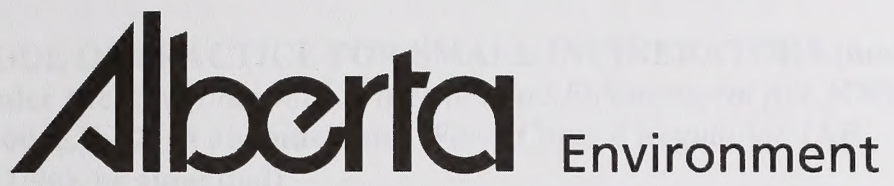

\title{
CODE OF PRACTICE FOR SMALL INCINERATORS
}

\section{September 2005}

made under the Environmental Protection and Enhancement Act

(C) Published by Alberta Queen's Printer

Queen's Printer Bookstore

Main Floor, Park Plaza

10611 - 98 Avenue

Edmonton, AB T5K 2P7

(780) $427-4952$

Fax (780) 452-0668

E-mail: qp@gov.ab.ca

Shop on-line at http://www.gov.ab.ca/qp 



\section{ALBERTA ENVIRONMENT}

CODE OF PRACTICE FOR SMALL INCINERATORS (made under the Environmental Protection and Enhancement Act, RSA 2000, c.E-12, as amended and Waste Control Regulation (AR 192/96), as amended)

Table of Contents

1. Definitions

2. General Requirements

3. Analytical Requirements

4. Registration Application/Administration Requirements

5. Design Requirements

6. Operational and Emission Requirements

7. Monitoring Requirements

8. Closure Requirements

9. Reporting Requirements

10. Record Keeping Requirements

11. Code of Practice Administration

Schedule 1 Registration Information for Small Incinerators 


\section{Section 1: Definitions}

1.1 All definitions in the Act and the regulations under the Act apply except where expressly defined in this Code of Practice.

1.2 In this Code of Practice:

(a) "Act" means the Environmental Protection and Enhancement Act, RSA 2000, c.E-12, as amended;

(b) "auxiliary burner" means a burner that fires auxiliary fuel in a small incinerator for the purpose of:

(i) preheating,

(ii) drying and igniting solid waste, or

(iii) maintaining adequate operating temperatures;

(c) "ISO 17025" means the international standard, developed and published by International Organization for Standardization (ISO), specifying the management and technical requirements for laboratories to demonstrate their technical competence to perform defined tests and produce valid data and results;

(d) "kPa" means kilopascal;

(e) "mg/kg" means milligrams per kilogram;

(f) “mg/L" means milligrams per litre;

(g) "mobile incinerator" means an incinerator that:

(i) is not fixed to any location, and

(ii) is operated at any one (1) location for a total of not more than 365 days in two (2) consecutive calendar years;

(h) "primary chamber" means the chamber of a small incinerator into which waste is added;

(i) "Professional Engineer" means a professional engineer or registered professional technologist (engineering) under the Engineering, Geological and Geophysical 
Professions Act or an equivalent professional designation from other jurisdiction;

(j) "registration holder" means a person who has been issued a registration under the Act for the construction, operation, or reclamation of a small incinerator;

(k) "regulations" mean the regulations under the Act;

(1) " $\mathrm{Rm}^{3}$ " means cubic metre of air at the reference conditions of twenty-five (25) degrees Celsius and $101.325 \mathrm{kPa}$;

(m) "secondary combustion chamber" also known as afterburner, means the chamber of a small incinerator where the flue gas from the primary chamber is heated to a temperature that will destroy the waste;

(n) "small incinerator" means:

(i) a mobile incinerator that, by means of burning under control conditions, treats waste that contains:

(A) halogenated organic compounds in an amount of not more than one thousand (1000) milligrams per kilogram of waste,

(B) polychlorinated biphenyls in an amount of not more than fifty (50) milligrams per kilogram of waste,

(C) lead in an amount of not more than one hundred (100) milligrams per kilogram of waste, or

(D) mercury in an amount of not more than two (2) milligrams per kilogram of waste; and

(ii) an incinerator that, by means of burning under controlled conditions, treats not more than ten (10) tonnes of waste per month, and:

(A) is fixed to one location, or 
(B) is operated at any one (1) location for a total of more than 365 days in two (2) consecutive calendar years,

but does not include an incinerator that:

(iii) is used by one single-family detached dwelling to burn household waste generated only by that household,

(iv) is used for burning kitchen camp wastes at a mining, construction, demolition, drilling or exploration site,

(v) is used for burning human bodies at a crematory that is licensed under the Cemeteries Act, or

(vi) is governed by an authorization issued under the Oil and Gas Conservation Act.

(o) "TEQ" means dioxin toxic equivalent with respect to the following toxicity equivalency factors:

Congeners

Toxicity Equivalency Factor

2,3,7,8-tetrachloro-dibenzo-p-dioxin

1.000

1,2,3,7,8-pentachloro-dibenzo-p-dioxin

0.500

1,2,3,4,7,8-hexachloro-dibenzo-p-dioxin

0.100

1,2,3,6,7,8-hexachloro-dibenzo-p-dioxin

0.100

1,2,3,7,8,9-hexachloro-dibenzo-p-dioxin

0.100

2,3,7,8-tetrachloro-dibenzofuran

0.100

1,2,3,7,8-pentachloro-dibenzofuran

0.050

2,3,4,7,8-pentachloro-dibenzofuran

0.500

1,2,3,4,7,8-hexachloro-dibenzofuran

0.100

1,2,3,6,7,8-hexachloro-dibenzofuran

0.100

1,2,3,7,8,9-hexachloro-dibenzofuran

0.100

2,3,4,6,7,8-hexachloro-dibenzofuran

0.100

(p) "thermal desorber" means a small incinerator that:

(i) uses indirect heat to separate volatile organic compounds from a waste, and 
(ii) destroys these volatile organic compounds in a combustion chamber; and

"this Code of Practice" means the Code of Practice for Small Incinerators, published by the Department, as amended.

\section{Section 2: General Requirements}

2.1 Any registration holder who operates a small incinerator, must do so in accordance with this Code of Practice.

2.2 Any conflict between the registration application and the terms and conditions of this Code of Practice shall be resolved in favour of this Code of Practice.

2.3 The terms and conditions of this Code of Practice do not affect any rights or obligations created under any other authorization issued by Alberta Environment.

2.4 The terms and conditions of this Code of Practice are severable. If any term or condition of this Code of Practice or the application of any term or condition is held invalid, the application of such term or condition to other circumstances and to the remainder of this Code of Practice shall not be affected by that invalidity.

2.5 Subject to 2.6, if the registration holder monitors for any substances or parameters which are the subject of limits in this Code of Practice more frequently than is required, using procedures authorized in this Code of Practice, then the registration holder shall provide the results of such monitoring as an addendum to the next reports required by this Code of Practice.

2.6 Section 2.5 does not apply to short term testing or monitoring of operational changes, new processes, or technologies that do not cause an adverse effect.

2.7 The registration holder shall immediately notify the Director in writing if any of the following events occur:

(a) the registration holder is served with a petition into bankruptcy;

(b) the registration holder files an assignment in bankruptcy or Notice of Intent to make a proposal; 
(c) a receiver or receiver-manager is appointed;

(d) an application for protection from creditors is filed for the benefit of the registration holder under any creditor protection legislation; or

(e) any of the assets, which are the subject matter of this Code of Practice, are seized for any reason.

\section{Section 3: Analytical Requirements}

3.1 Any sample required pursuant to this Code of Practice shall be:

(a) collected;

(b) preserved;

(c) stored;

(d) handled; and

(e) analysed

in accordance with:

(i) the Test Methods for Evaluating Solid Waste, Physical/Chemical Methods, SW-846, published by the United States Environmental Protection Agency, 1998, as amended,

(ii) the Alberta Stack Sampling Code, published by Alberta Environment, 1995, as amended,

(iii) the Methods Manual for Chemical Analysis of Atmospheric Pollutants, AEC V93-M1, Alberta Environmental Centre, 1993, as amended,

(iv) the Air Monitoring Directive, Alberta Environment, 1989, as amended,

(v) the Standard Methods for the Examination of Water and Waste Water, 20 ${ }^{\text {th }}$ edition, 1998, published by the American Public Health Association, American Water Works Association, and Water Environment Federation, as amended, or 
(vi) any other equivalent method authorized in advance in writing by the Director.

3.2 The registration holder shall analyse all samples that are required to be obtained by this Code of Practice in a laboratory accredited pursuant to ISO 17025 standard, as amended, for the specific parameter(s) to be analysed, unless otherwise authorized in writing by the Director.

3.3 The registration holder shall comply with the terms and conditions of any written authorization issued by the Director under 3.2 .

\section{Section 4: Registration Application / Administration Requirements}

4.1 An application for a registration of a small incinerator shall contain, at a minimum, the information specified in Schedule 1.

4.2 The technical assessment of the small incinerator referred to in clause ( $f$ ) of Schedule 1 shall be signed and stamped by a Professional Engineer, the manufacturer, or the supplier of the equipment.

4.3 Where a registration has been issued regarding a particular small incinerator, that registration applies only to that small incinerator, and shall not be applied to any other small incinerator.

4.4 A registration holder shall provide written notice to the Director within fourteen (14) calendar days of any change in the information provided in the application for the registration, regarding:

(a) the maximum volume of wastes to be treated on a monthly basis;

(b) change in the chemical characteristics of the wastes that affects the classification of the waste;

(c) the name, address, and phone number of the registration holder; and

(d) the name, address, and phone number of the person who has charge, management, or control of the small incinerator. 


\section{Section 5: Design Requirements}

5.1 No person shall operate a small incinerator that has no secondary chamber unless the small incinerator is equipped with:

(a) an auxiliary burner;

(b) a spark arrestor;

(c) a temperature recording system, which:

(i) measures, and

(ii) continuously records

the temperature of the flue gas in the primary chamber, subject to 5.5; and

(d) a flue gas stack with a top that is at an elevation of at least:

(i) four (4) metres above the ground, and

(ii) two (2) metres above any natural or man-made structure located within ten (10) metres of the small incinerator.

5.2 No person shall operate a small incinerator that has both a primary combustion chamber and a secondary combustion chamber unless the small incinerator is equipped with:

(a) an auxiliary burner;

(b) a temperature recording system, which:

(i) measures, and

(ii) continuously records

the temperature of the flue gas in the primary combustion chamber, subject to 5.5 ;

(c) a temperature recording system which:

(i) measures, and 
(ii) continuously records

the temperature of the flue gas in the secondary chamber, subject to 5.5 ; and

(d) a flue gas stack with a top that is at an elevation of at least:

(i) four (4) metres above the ground, and

(ii) two (2) metres above any natural or man-made structure located within ten (10) metres of the small incinerator.

5.3 Subsections 5.1(d) and 5.2(d) do not apply where the small incinerator is operated at a location that is 1.5 kilometres or more from:

(a) the boundary of a city, town, village, hamlet, or summer village; or

(b) a residence or business.

5.4 The temperature of:

(a) the flue gas in the primary combustion chamber; and

(b) the flue gas in the secondary combustion chamber

shall be recorded continuously, subject to 5.5 .

5.5 The temperature recording system referred to in 5.1(c)(ii), 5.2(b)(ii), and 5.2(c)(ii) is not required to be continuous in the combustion chambers of:

(a) batch small incinerators that burn less than ninety (90) kilograms of non-hazardous waste per hour; or

(b) thermal desorbers used for the removal of nonhalogenated organic compounds from waste or contaminated soil.

5.6 The temperature recording system for the small incinerators referred to in 5.5(a) and (b) shall:

(a) measure; and 
(b) record

the temperature of the flue gas in the combustion chamber or in the treated waste or soil, as applicable, while the waste is being burned.

\section{Section 6: Operational and Emission Requirements}

6.1 The registration holder operating a small incinerator that has no secondary combustion chamber shall not burn waste that contains any of the following:

(a) halogenated organic compounds in a total amount greater than fifty (50) $\mathrm{mg} / \mathrm{kg}$ of waste;

(b) lead in an amount greater than one hundred (100) $\mathrm{mg} / \mathrm{kg}$ of waste; or

(c) mercury in an amount greater than two (2) $\mathrm{mg} / \mathrm{kg}$ of waste.

6.2 Subject to 6.3, emissions from a small incinerator shall not exceed any of the following limits:

(a) a maximum one (1) hour average concentration of fifty (50) milligrams of particulate matter per $\mathrm{Rm}^{3}$;

(b) a maximum one hour average concentration of seventy five (75) milligrams of hydrogen chloride per $\mathrm{Rm}^{3}$;

(c) a maximum one hour average concentration of fifty seven (57) milligrams of carbon monoxide per $\mathrm{Rm}^{3}$;

(d) visible emissions of twenty (20) percent opacity averaged over a period of six (6) consecutive minutes, determined in accordance with Part 1 of the Substance Release Regulation (AR 124/93);

(e) a maximum one hour average concentration of eighty (80) pg TEQ of dioxins and furans per $\mathrm{Rm}^{3}$; and

(f) a maximum one hour average concentration of twenty (20) $\mu \mathrm{g}$ of mercury per $\mathrm{Rm}^{3}$. 
6.3 The emission limits in 6.2(e) and (f) apply only to a small incinerator that has both a primary combustion chamber and a secondary combustion chamber if the following criteria are met:

(a) the registration holder burns waste with:

(i) halogenated organic compounds at levels which exceed a total amount greater than fifty (50) $\mathrm{mg} / \mathrm{kg}$ of waste, or

(ii) mercury in an amount greater than two (2) $\mathrm{mg} / \mathrm{kg}$ of waste; and

(b) the burning is done on or after January 1, 2006.

6.4 Subject to 6.6 , no person shall operate a small incinerator that has no secondary combustion chamber unless the operating temperature is at least five hundred (500) degrees Celsius.

6.5 Subject to 6.6 , no person shall operate a small incinerator that is equipped with both a primary combustion chamber and a secondary combustion chamber unless the operating temperatures are at least:

(a) Five-hundred (500) degrees Celsius in the primary combustion chamber; and

(b) Eight hundred seventy (870) degrees Celsius in the secondary combustion chamber.

6.6 No person shall operate a thermal desorber unless:

(a) the temperature in the combustion chamber is greater than the boiling point of the least volatile chemical constituent in the waste or contaminated soil being treated; and

(b) the operation complies with the design, operation, and control systems of the small incinerator, as specified by the manufacturer.

6.7 All wastes and wastewater resulting from the small incinerator shall be:

(a) handled in compliance with the Waste Control Regulation; and 
(b) disposed of or recycled in a manner authorized under the Act.

\section{Section 7: Monitoring Requirements}

7.1 The monitoring referred to in 5.6 for the temperature of the flue gas in the combustion chamber or in the treated waste or soil, as applicable, shall be conducted at least once per day or once for each different batch of wastes being processed, whichever represents a shorter period.

7.2 Prior to, or during operation of the small incinerator, and as often as there is a change in the nature of the waste burned, the registration holder shall collect data on:

(a) the waste characteristics, including the parameters specified in 6.1 ; and

(b) the expected or actual emissions as specified in 6.2.

7.3 Subject to 7.4, a person responsible for a small incinerator shall complete a manual stack survey:

(a) within six (6) months of commencement of burning waste that contains:

(i) halogenated organic compounds in a total amount greater than fifty $(50) \mathrm{mg} / \mathrm{kg}$ of waste,

(ii) lead in an amount greater than one-hundred (100) $\mathrm{mg} / \mathrm{kg}$ of waste,

(iii) mercury in an amount greater than two (2) $\mathrm{mg} / \mathrm{kg}$ of waste; or

(b) as requested in writing by the Director.

7.4 Upon application and submission by the person responsible for the small incinerator the Director may exempt the person from the test under 7.3. by notice in writing.

7.5 At least two (2) weeks prior to conducting a manual stack survey required in 7.3 , the registration holder shall notify the Director in writing that the manual stack survey will be undertaken. 
7.6 The manual stack survey required under section 7.3 shall meet the following requirements:

(a) the stack gas must be analysed for the parameters set out in section 6.2, as applicable;

(b) the operating temperatures of all combustion chambers must be recorded; and

(c) the manual stack survey must comply with the sampling procedures in the Alberta Stack Sampling Code, 1995, published by Alberta Environment, as amended.

7.7 In addition to the collection and analysis of samples under this Code of Practice, the registration holder shall:

(a) collect;

(b) analyse; and

(c) provide the Director with results of

any additional samples that are required in writing by the Director.

\section{Section 8: Closure Requirements}

8.1 Where a small incinerator:

(a) has ceased operations permanently; or

(b) has not been operated for a period of twelve (12) consecutive months;

the registration holder shall notify the Director in writing within thirty (30) calendar days after the respective event.

\section{Section 9: Reporting Requirements}

9.1 In addition to any other reporting required pursuant to this Code of Practice, the Act, or the regulations, the registration holder shall immediately report any contravention of this Code of Practice to the Director, either:

(a) by telephone at (780) $422-4505$; or 
(b) by a method:

(i) in compliance with the release reporting provisions in the Act and the regulations, or

(ii) authorized in writing by the Director.

9.2 In addition to the immediate report in 9.1, the registration holder shall provide a report to the Director:

(a) in writing; or

(b) by a method:

(i) in compliance with the release reporting provisions in the Act and the regulations, or

(ii) authorized in writing by the Director

within seven (7) calendar days of the discovery of the contravention, or within a time period specified in writing by the Director, unless the Director waives the requirement for a report.

9.3 The report required under 9.2 shall contain, at a minimum, the following information:

(a) a description of the contravention;

(b) the date, time, and duration of the contravention;

(c) the address or legal land description (LLD) of the location of the contravention;

(d) the name of the registered owner or owners of the land on which the contravention occurred;

(e) the name, address, phone number, and responsibilities of all persons operating the small incinerator at the time the contravention occurred;

(f) an explanation as to why the contravention occurred including, but not limited to, a comparison of operating conditions at the time the contravention to normal operating conditions; 
(g) a summary of all measures and actions that were taken to mitigate any effects of the contravention;

(h) a summary of all measures that will be taken to address the remaining effects and potential effects related to the contravention;

(i) the name, address, phone number, and responsibilities of all persons who had charge, management, or control of the small incinerator at the time the contravention occurred;

(j) a summary of proposed measures that will prevent future contraventions, including a schedule of implementation for these measures;

(k) any information that was maintained or recorded under this Code of Practice, as a result of the incident; and

(1) any other information required by the Director in writing.

9.4 A registration holder, who is required to complete a manual stack survey under 7.3 shall, within sixty (60) days of completion of the manual stack survey, provide to the Director a copy of the manual stack survey results.

\section{Section 10: Record Keeping Requirements}

10.1 The registration holder shall:

(a) record the following information;

(b) maintain the following information; and

(c) keep the following information available for five (5) years after the creation of the record:

(i) all records that are required under this Code of Practice,

(ii) the results of any recording, monitoring, analysis, and any stack testing that are carried on pursuant to this Code of Practice, including the method of testing used, 
(iii) the source, quantity, and characteristics of waste incinerated on a per monthly basis,

(iv) the quantity, type, and disposal location of all wastes resulting from operation of the small incinerator, on a monthly basis,

(v) a description of all maintenance and repairs made to the small incinerator including:

(A) the date of the maintenance;

(B) a description of the maintenance conducted; and

(C) the name of person conducting the maintenance,

(vi) a copy of all applications submitted to the Department for a registration,

(vii) design drawings and specifications for the small incinerator,

(viii) all reports of inspections conducted by the Department,

(ix) the registration issued under the Act for the activity, and

(x) all correspondence with the Department regarding the small incinerator.

10.2 The results and records in 10.1(a) and 10.1(c) shall contain, at a minimum, all of the following information:

(a) the date, place, and time of monitoring, and the name of the person collecting the sample;

(b) the date of analysis;

(c) the laboratory name and person responsible for performing analysis;

(d) the analytical method used; and 
(e) the results of the analysis.

10.3 Prior to commencing operation of a mobile incinerator at a new location, the person responsible shall prepare an information sheet, which shall include, but is not limited to, the following information with respect to the small incinerator:

(a) the registration;

(b) the name, address, and phone number of the person who holds the registration;

(c) the name of the company and/or persons who will have control of the mobile incinerator on behalf of the registration holder;

(d) the name, address, and phone number of the person responsible for the small incinerator;

(e) the name and mailing address of the waste generator from whom the waste was received;

(f) the name and address of the registered owner of the land on which the mobile incinerator will operate;

(g) a site plan showing the proposed operating location;

(h) a map showing water bodies, residences, institutions, and commercial and industrial developments within a 1.5 kilometre radius of the site at which the small incinerator will operate; and

(i) the planned duration of the operation.

10.4 The requirements in 10.3 do not apply to a mobile incinerator that:

(a) operates for less than seven (7) days in two (2) consecutive months at the same location; and

(b) burns less than ten (10) tonnes of waste per month.

10.5 A registration holder shall, upon request by an inspector or Director, provide to the inspector or Director, a copy of the registration issued under the Act, any accompanying 
correspondence, and any records or data regarding the small incinerator.

\section{Section 11: Code of Practice Administration}

11.1 This Code of Practice will be reviewed as changes in technological and other standards warrant. 


\section{SCHEDULE 1}

\section{REGISTRATION INFORMATION FOR SMALL INCINERATORS}

Pursuant to 4.1 of this Code of Practice, all of the following information shall be provided to the Director:

(a) The name of the intended registration holder, their address, phone number, facsimile number, and e-mail address;

(b) The company name (if any) and the name, job title, address, phone number, facsimile number, e-mail address, and signature of the person who submitted the registration application on behalf of the intended registration holder;

(c) If a person other than the intended registration holder submitted the registration application, written authorization is required from the intended registration holder, stating that the person who submitted the registration application was authorized to do so on behalf of the intended registration holder;

(d) The name, job title, address, phone number, facsimile number, and e-mail address of the person designated by the intended registration holder as the primary contact for the small incinerator;

(e) The municipal address (if one exists), or legal land description (LLD) on which the small incinerator is or will be located;

(f) A technical assessment of the small incinerator, which includes but is not limited to:

(i) the make, model, and serial number of the incinerator,

(ii) type of incinerator,

(iii) the design and number of combustion chambers,

(iv) the operating temperature(s) of the combustion chambers,

(v) the operating temperatures of the desorption and combustion chambers of a thermal desorber,

(vi) any modifications to the small incinerator, 
(vii) equipment to be used in conjunction with the small incinerator,

(viii) the actual and rated capacity, as specified by the manufacturer, in kilograms per hour,

(ix) the source, quantity, and chemical characteristics of wastes or contaminated soils expected to be processed,

(x) the proposed disposal location of any wastes resulting from the operation, and

(xi) monitoring to be conducted.

In consideration of the information required above, and the information required in an Activities Plan, the Director waives the requirements of subsection 3(1)(a) through (o) of the Approvals and Registrations Procedure Regulation, A.R. 113/93, as amended from time to time, for a registration application under this Code of Practice. 

